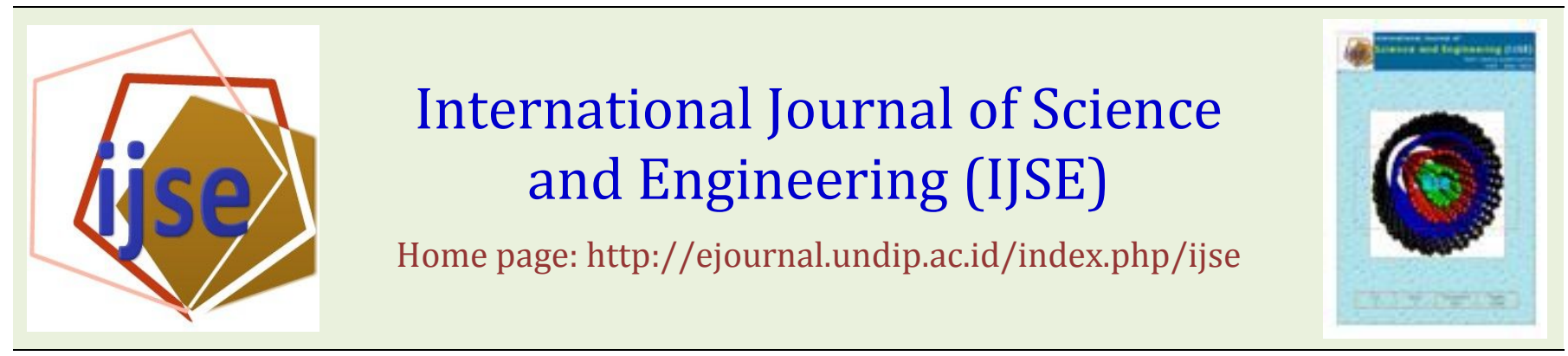

\title{
The use of geomatic techniques to monitor environmental deformation
}

\author{
Samih Al Rawashdeh11), Rami E. Al Ruzouq2), and Khaldoun S. Qtaishat ${ }^{3)}$
}

1) Dept. of Surveying and Geomatics Engrg., Fac. of Engrg., Al-Balqa' Applied University, Al-Salt 19117, Jordan

2)Dept. of Surveying and Geomatics Engrg., Fac. of Engrg., Al-Balqa' Applied University, Al-Salt 19117, Jordan,

3) Mu'tah University, Faculty of Engineering, Department of civil Engineering,

E-mail: rsamihehotmail.com ; samih_alrawashdeh@yahoo.com

khaldoun_Q@hotmail.com

\begin{abstract}
$\overline{\text { Abstract - Geospatial deformations are very important in some countries and may lead to catastrophes. For this purpose we need to find }}$ practical accurate ways to provide continuous monitoring and measurement to allow protection and secure safety. Some countries are suffering great losses such as Jordan where the major high way that connects the north to the middle of the country is closed most of the winter due to landslides that push the road away. In this work we are employing new Geomatics technique to analyze, monitor and measure the landslides. An application of geodetic monitoring of a major landslide on the highway linked Amman to the north (Jerash, Irbid). For the purpose of monitoring the landslide we designed a geodetic network, which consists of 4 points. Measurements were carried out over the period 2007 to 2012 (before and after rainy season) of 12 points within the network. The obtained results are compared to results published previously using different techniques of measurement over the two years period (2002-2004). In the new methodology, GPS receivers and total stations of high precision were used in addition to an orthophoto of two aerial photographs. The observations adjustment and the deformation analysis were executed using locally developed computer programs. The study enabled us to determine a value of $0.26 \mathrm{~m} /$ year as an average displacement of the landslide-prone area for the period of 2007-2012.

Key words - GPS; Field surveying; deformation measurements;land slides.
\end{abstract}

Submission: February 28, $2012 \quad$ Corrected : March 13, 2013

Accepted: March 27, 2013

Doi: $10.12777 /$ ijse.4.2.2013.92-96

[How to cite this article: Rawashdeh, S., Ruzouq, R.E., and Qtaishat, K.S.. (2013). The use of geomatic techniques to monitor environmental deformation. International Journal of Science and Engineering, 4(2),92-96. Doi: 10.12777/ijse.4.2.2013.92-96]

\section{INTRODUCTION}

The advancement of the computing abilities led to the creation of new sciences to include Geomatics engineering, which visa versa opened new heavens for scientists to employ and provide better methodologies to achieve their goals. Landslides and geospatial deformation were the subject of many studies during the three previous decades $[4,9,10,15]$. Modern geomatic techniques are developing rapidly and offer greater possibilities and efficiencies everyday. Jordan suffers the problem of landslides at many important locations due to (1). The special geology and structure of land; (2). The topography ; (3). The annual quantity of rainfall.

The Amman-Irbid dual carriage international highway is the major way to link Amman/Jordan to the Syrian borders (Figure 1).

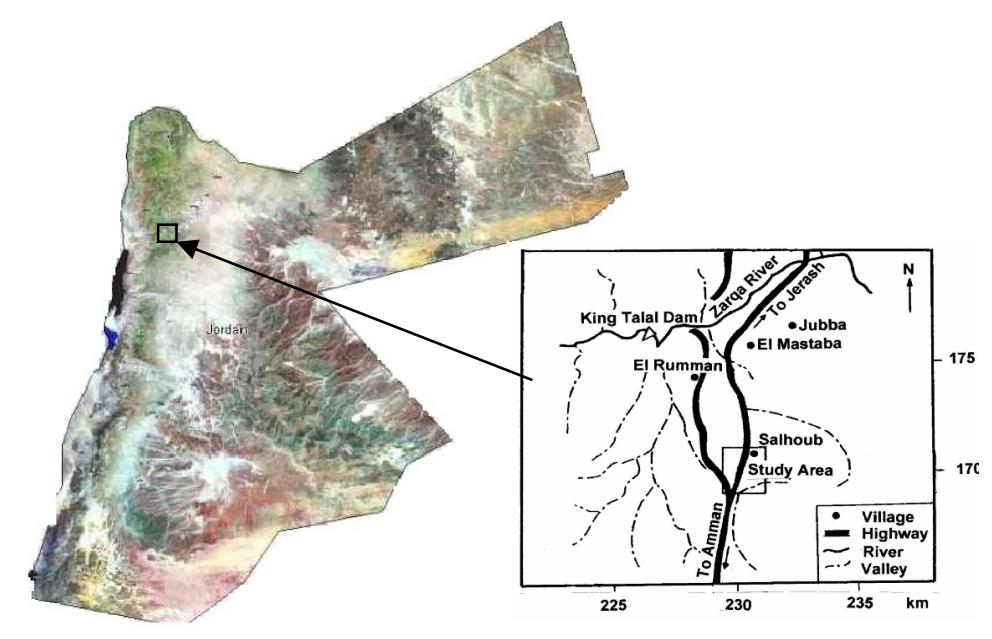

Figure 1. Study area

The topography over most of the highway route is mountainous terrain, hence cut and fill construction of the 
road corridor was continuously adopted. Cuts were made into deeply weathered rock masses and/or alternating of sandy, silty sandy and clayey sedimentary rocks $[1,2]$. Geological, Engineering and Hydrological Evaluation of Landslides in Jordan were repeatedly analyzed and studied to control the landslide problem and reports submitted to the Higher Council for Science and Technology, Amman, Jordan. The findings always clarified that the road carriage is constructed within units composed of marls and clays intercalated with marly limestone, limestones, nodular limestones and dolomites. Ultimately several slopes have become unstable due to the naturally unfavorably orientation of stratification, bedding planes and joints. Furthermore, many road embankments were constructed on colluvial slopes which are geomorphologically unstable [12].

Different Landslides occurred across the highway from the start and when under construction such as during the snowy and very wet winter 1991-1992 along the highway, [12]. Geotechnical investigations were carried out by three companies after embankment and cut-slope failures. The investigation consisted of geological mapping, geotechnical borehole drilling, geophysical surveys, laboratory testing of soil and rock core samples and failure analysis with emphasis on stability assessment [8]. Another study was carried out where they used remote sensing after the catastrophic failures along the highway in order to prepare a landslide hazard zonation map of the whole area [12]. It is found that the zones where the failures occurred are being subjected to continuous landslides and should have been avoided during the construction of the highway.

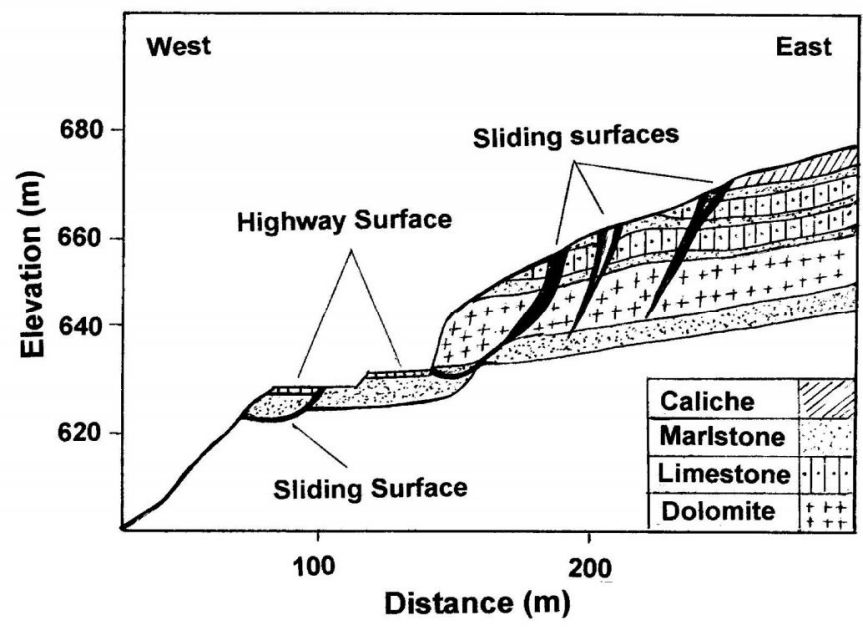

Figure 2. Geological X-Sec profile (caliches, limestone, dolomite and marlstone).

After the achievement of the highway construction, it was necessary to monitor a major landslide in the area using geodetic techniques. The objectives of this monitoring are the study of the carriageway stability and the prediction of any important failures in the area. The landslide is located in a hilly area to the east of the highway, at $6 \mathrm{~km}$ to the north of Amman. The outcropping rocks in the study area are all sedimentary rocks, which belong to the cretaceous age. The geological cross-section in the studied area (Fig. 2) shows a marlstone layer in the bottom, a dolomite layer, a limestone layer and a caliche layer on the top (Malkawi et al.). The exposed rocks in the study area show well-developed joints and cracks, the extension of these joints and cracks ranges from few centimeters to several meters. It shows as well the presence of discontinuities form slide surfaces along which sliding may take place.

The aerial photos taken in 1992, during the highway construction show an old landslide in the area. In addition, all the landslides within the area are above the highway embankment and the mass movement along these landslides is rotational towards west and North West direction.

\section{MATERIAL AND METHOD}

\section{Description of the Geodetic Network and Measurements}

From the network of fifty-six points was established in the study area inside the landslide-prone area in 2002, 11 points only were identified over all the period 2007-2012 (Figure 3).

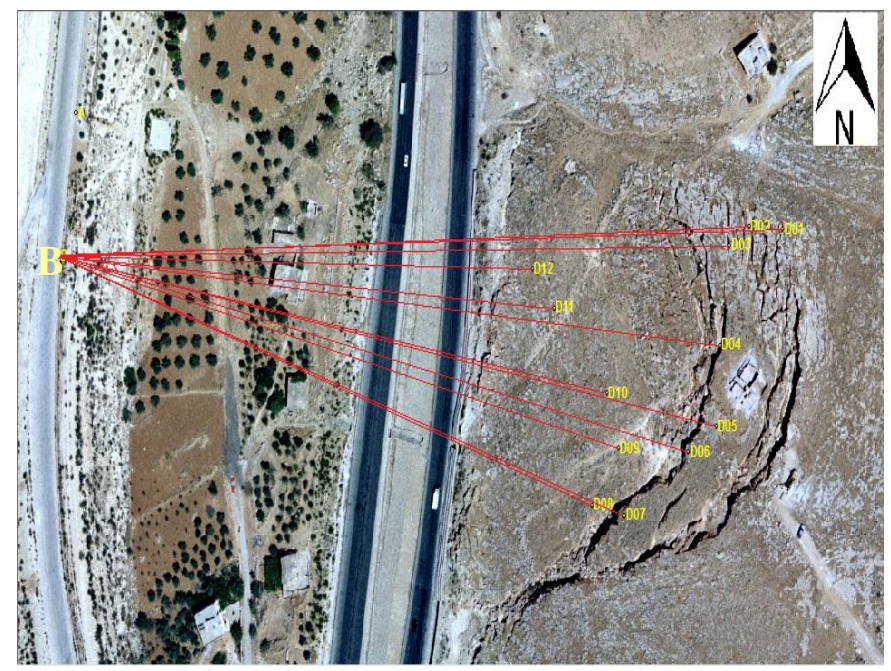

Figure 3. The observations from a geodetic point of view (May 2008).

$$
w_{e}=\frac{\sigma_{e}^{2}}{\sigma_{0}^{2}} \in F\left(r_{e}, r\right) \ldots \ldots \ldots \ldots . .1
$$

Measurements were carried out using GPS and total stations of high precision at different times, before and after the rainy season. The stations of the reference GPS network have been selected outside the landslide-prone area and monumented in a stable geological zone. The aim of GPS network is to be used as a reference for other GPS techniques like Rapid static, Stop and Go, or Real Time Kinematics (RTK) survey. In order to confirm the stability of reference GPS network, seven parameter transformations have been determined between two epochs. We noticed that the residuals are very small with a small scale factor $(-3.0324 \mathrm{~mm} / \mathrm{km})$, which confirm the GPS network stability during the first year of monitoring. 


\section{Geometrical analysis of deformations}

As the amplitude of deformation is unknown, The conventional survey has been used to determine the landslide monitoring to evaluate the displacements of the mass in the study area. Full analysis and statistical testing of the results are required [5,7]. In the computation part of our work, the following steps were considered [8]:

1. Statistical testing of deformation model and the choice of the best model involve a global test on the goodness of fit of the model, and on the significance of individual deformation parameters. All the results were adjusted.

2. The goodness of fit of a postulated deformation model is done using the known statistic $w_{e}$. Under the null hypotheses, $\mathrm{H}_{0}$ follows Fisher distribution $F\left(r_{e}, r\right)$ :

Where $\sigma_{e}^{2}$ and $r_{e}$ are respectively the posterior estimated variance factor and degrees of freedom of coordinate differences of two epochs, $\sigma_{0}^{2}$ and $r$ are respectively the weighted variance factor and degrees of freedom associated with the separate network adjustment of different epochs. $\sigma_{0}^{2}$ can be expressed as follows:

$$
\sigma_{0}^{2}=\frac{r_{1} \hat{\sigma}_{01}^{2}+r_{2} \hat{\sigma}_{02}^{2}}{r_{1}+r_{2}}
$$

$r_{1}, r_{2}$ and $\hat{\sigma}_{01}^{2}, \hat{\sigma}_{02}^{2}$ are respectively the redundancies and the variances of unit weight of the two adjustments.

Given the significance level $\alpha$, the Null hypothesis is accepted if $w_{e} \leq F_{I-\alpha}\left(r_{e}, r\right)$, otherwise, the postulated deformation model is considered inappropriate [11]. After that, the test on the significance of coordinate differences is applied by using the known statistic:

$$
y_{e}=\frac{\delta \hat{x}^{T} Q_{\delta \delta}^{-1} \delta \hat{x}}{m \sigma_{0}^{2}}
$$

where $y_{e}$ belongs to Fisher $F_{m,\left(r_{1}+r_{2}\right), \alpha}$ distribution:

$y_{e} \sim F_{m,\left(r_{1}+r_{2}\right), \alpha}$ if $H_{0}: \hat{x}_{1}=\hat{x}_{2}$ is true

$Q_{\delta \delta}$ is the cofactor matrix of the coordinate differences and $\mathrm{m}$ is the number of tested unknown parameters. If $y_{e} \leq F_{m,\left(r_{1}+r_{2}\right), \alpha}$, the hypothesis $\mathrm{H}_{\mathrm{o}}$ is accepted and consequently there is no deformation between the two epochs, but if $y_{e}>F_{m,\left(r_{1}+r_{2}\right), \alpha}$, Significant changes in coordinates were observed, after the global test, which is able to put in evidence eventual global significant variations [8]. Table 1 shows that only 11 points where significant variations occurred. The table also shows the statistical test values, which should be compared with Fisher critical value computed as 2.067 at $99 \%$ level.
Other GPS techniques to monitor the landslide like Stop \& Go and RTK survey due to the large amplitude of the obtained deformations. Stop \& Go and RTK GPS techniques provide an accuracy of (0.02 - 0.04) $\mathrm{m}$ [6], which is acceptable for our study.

Duel frequency GPS receivers with radio link equipment were used to carryout this survey. Measurements during the study period were performed during the second year of monitoring. The accuracy of RTK measurement, which is estimated at 0.02 to $0.04 \mathrm{~m}$ $[6,15]$, depends on the baseline length [1], atmospheric condition and ambiguity resolution OTF (On The Fly) [14]. The time necessary for carrying out the RTK survey and processing the data is $1 / 5$ of the time needed for a conventional survey. The deformation between two epochs using the RTK survey is obtained by comparing directly the coordinates of the two epochs without the calculations of geometrical analysis of deformation. Before the comparison, the systematic errors between the two epochs are eliminated by applying the seven parameter transformations obtained from the reference GPS network, and the error ellipsis are taken into consideration.

\section{RESULTS AND DISCUSSION}

Table 1 presents the observations of the ground control points in $\mathrm{x}$ and $\mathrm{y}$ coordinates during the study period 2007 - 2012. The measurements were carried out twice a year, before and after the rainy season, for 12 points within the network. The study started in November 2007 by the observation of 56 points in $\mathrm{x}, \mathrm{y}$ and $\mathrm{z}$. In May 2012 we presumed the analysis with only 11 points as we were unable to find the rest of the points due to severe land slides in the study area.

The eleven points were located in an orthophoto built by two aerial photographs using GIS software. In the new methodology, high precision GPS receivers and total stations were used, to perform the analysis, in addition to the orthophoto to clarify the direction and the location of the displacement. The two different methods of measurements: GPS and conventional survey provided similar results.

Tables 2 and 3 present the displacements in $\mathrm{x}$ and $\mathrm{y}$ over the period 2007-2012. The displacements are very high in value which explains the instability of this area. Many remarks can be observed in looking to these tables:

1. The displacements vary in direction and in value depending on the type of rock and soil type (Figure 4).

2. The value of displacement is proportional to the quantity of rainfall.

3. The displacement over the period varies from 0.60 meter to 1.92 meter.

4. This displacement decreases over time, but still very dangerous.

5. The displacement values are above the accepted values.

6. There are no significant differences between the results of displacement measurements using the RTK GPS and conventional techniques. 


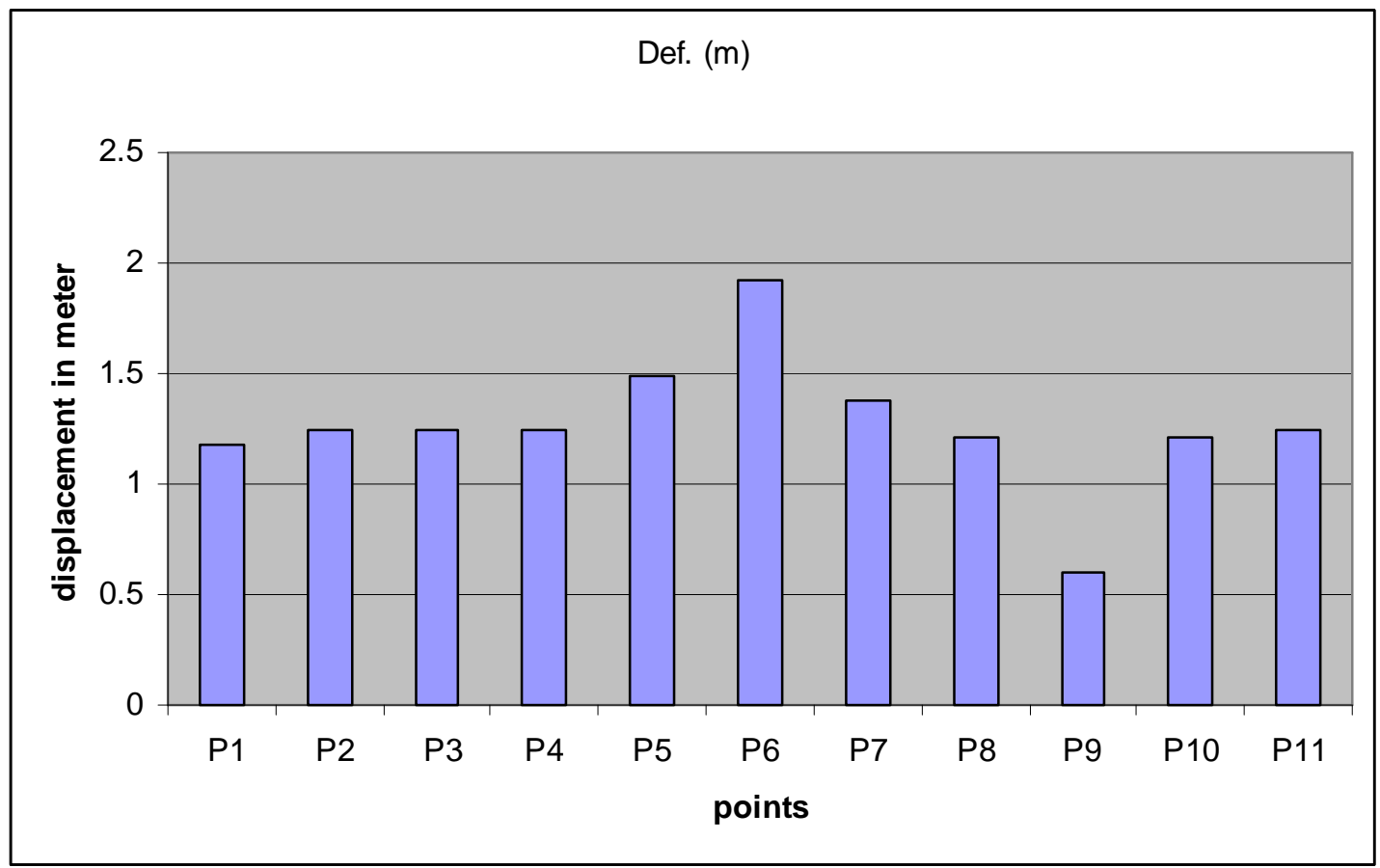

Figure 4. Displacement of points in meter over time.

Table 1. Coordinates and displacement of 12 GCP points in the study area

\begin{tabular}{|l|c|c|c|c|c|c|c|c|}
\hline & \multicolumn{2}{|c|}{$27 / 11 / 2007$} & \multicolumn{2}{c|}{$10 / 05 / 2008$} & \multicolumn{2}{c|}{$13 / 11 / 2011$} & \multicolumn{2}{c|}{$20 / 05 / 2012$} \\
\hline ID & $\mathrm{x}$ & $\mathrm{y}$ & $\mathrm{x}$ & $\mathrm{y}$ & $\mathrm{x}$ & $\mathrm{y}$ & $\mathrm{x}$ & $\mathrm{y}$ \\
\hline P1 & 769446.41 & 3556743.22 & 769446.30 & 3556743.30 & 769445.40 & 3556743.51 & 769445.29 & 3556743.59 \\
\hline P2 & 769446.01 & 3556759.82 & 769445.83 & 3556759.80 & 769445.01 & 3556759.10 & 769444.87 & 3556758.90 \\
\hline P3 & 769371.92 & 3556778.69 & 769371.78 & 3556778.76 & 769370.73 & 3556778.91 & 769370.62 & 3556778.98 \\
\hline P4 & 769453.80 & 3556724.77 & 769453.70 & 3556724.83 & 769452.69 & 3556725.03 & 769452.59 & 3556725.11 \\
\hline P5 & 769452.44 & 3556712.34 & 769452.31 & 3556712.38 & 769451.01 & 3556711.48 & 769450.95 & 3556711.39 \\
\hline P6 & 769435.02 & 3556682.13 & 769434.89 & 3556682.20 & 769433.32 & 3556682.54 & 769433.20 & 3556682.63 \\
\hline P7 & 769431.28 & 3556713.57 & 769431.22 & 3556713.63 & 769430.03 & 3556713.95 & 769429.91 & 3556713.96 \\
\hline P8 & 769353.29 & 3556712.47 & 769353.41 & 3556712.49 & 769352.50 & 3556712.61 & 769352.41 & 3556712.76 \\
\hline P9 & 769357.04 & 3556660.37 & 769357.01 & 3556660.39 & 769356.60 & 3556660.63 & 769356.51 & 3556660.76 \\
\hline P10 & 769435.05 & 3556754.20 & 769434.89 & 3556754.29 & 769333.97 & 3556754.79 & 7693333.86 & 3556754.89 \\
\hline P11 & 769412.78 & 3556774.52 & 769412.67 & 3556774.59 & 769411.61 & 3556774.01 & 769411.52 & 3556774.21 \\
\hline
\end{tabular}

Table 2. Displacement of points over the period of 2007 - 2011, before and after the rainy season.

\begin{tabular}{|c|c|c|}
\hline points & $\begin{array}{l}\text { Def. } \\
\text { (m) }\end{array}$ & $\begin{array}{c}\text { Average } \\
\text { displacement per } \\
\text { year in meter }\end{array}$ \\
\hline P1 & 1.18 & \multirow{11}{*}{$0.256 \mathrm{~m}$ per year } \\
\hline $\mathrm{P} 2$ & 1.25 & \\
\hline P3 & 1.25 & \\
\hline $\mathrm{P} 4$ & 1.24 & \\
\hline P5 & 1.49 & \\
\hline P6 & 1.92 & \\
\hline P7 & 1.38 & \\
\hline P8 & 1.21 & \\
\hline P9 & 0.60 & \\
\hline P10 & 1.21 & \\
\hline P11 & 1.24 & \\
\hline
\end{tabular}

Table3. Annual displacement of the mass in the study area during the period 2007-2012

\begin{tabular}{|c|c|c|c|c|}
\hline period & \multicolumn{2}{|c|}{$\begin{array}{c}27 / 11 / 2007- \\
10 / 05 / 2008\end{array}$} & \multicolumn{2}{c|}{$\begin{array}{c}10 / 05 / 2008- \\
13 / 11 / 2011\end{array}$} \\
\hline $\begin{array}{c}\text { Deformat } \\
\text { ion }\end{array}$ & $\begin{array}{c}\Delta \mathrm{x} \\
(\mathrm{m})\end{array}$ & $\begin{array}{c}\Delta \mathrm{y} \\
(\mathrm{m})\end{array}$ & $\begin{array}{c}\Delta \mathrm{x} \\
(\mathrm{m})\end{array}$ & $\begin{array}{c}\Delta \mathrm{y} \\
(\mathrm{m})\end{array}$ \\
\hline P1 & 0.11 & 0.08 & 0.90 & 0.21 \\
\hline P2 & 0.18 & 0.02 & 0.82 & 0.30 \\
\hline P3 & 0.14 & 0.07 & 1.05 & 0.16 \\
\hline P4 & 0.10 & 0.20 & 1.01 & 0.08 \\
\hline P5 & 0.13 & 0.04 & 1.29 & 0.08 \\
\hline P6 & 0.13 & 0.07 & 1.67 & 0.07 \\
\hline P7 & 0.06 & 0.06 & 1.19 & 0.01 \\
\hline P8 & 0.12 & 0.02 & 0.91 & 0.15 \\
\hline P9 & 0.03 & 0.02 & 0.41 & 0.13 \\
\hline P10 & 0.16 & 0.09 & 0.92 & 0.10 \\
\hline P11 & 0.11 & 0.07 & 1.07 & 0.20 \\
\hline
\end{tabular}


Finally, the obtained results are compared to results published previously using different technique of measurements over the period 2002-2004. Our results show an annual displacement for the landslide-prone area of an average $0.26 \mathrm{~m} /$ year Table 3. Meanwhile, the rate of the displacement in the previous study over the period 2002 to 2007 was evaluated at 0.42 meter.

The orthophoto shows severe cracks in the area, which led to great damage in the road. In addition, a complete damage to the retaining wall which was constructed to keep the road from the effect of land slides. Therefore the construction of an alternative road, parallel to the existing road to deviate the traffic in case of a failure is very important. Then, continuous monitoring of the road is imperative to avoid any catastrophic failure.

\section{CONCLUSIONS}

Modern GPS and conventional surveys techniques were used in this work. The results achieved were close to each other. The study proved the efficiency of geomatics techniques for landslide monitoring in case of large deformation. The RTK GPS technique provides fast, economical and labor saving method to monitor displacements. The obtained results were compared to results of another work conducted over the two years period (2002-2004). This comparison shows a difference of $0.16 \mathrm{~cm}$. this may be due to:

1) The used method followed in

2) The choice of the ground control points.

3) Or to the decrease of displacement over time. Analyzing the movement of the landslides in the landslideprone area, we concluded the following: (i). The observed annual deformation ranged from $0.00 \mathrm{~m}$ to $1.92 \mathrm{~m}$, at different points in the landslide-prone area; (ii). Cracks are likely to occur in the area, in case of heavy rains, which may damage the road; (iii). The construction of an alternative road, parallel to the existing road to deviate the traffic in case of a failure; (iv). The road should be continuously and in case of a heavy rain monitored to avoid any catastrophic failure.

\section{REFERENCES}

[1]. Al-Bayari, O., and Unguendoli, M., 2002. Experiences in GPS
Control Networks Computation. Proceedings of the Fifth Bilateral Geodetic Meeting Italy-Poland, Monselece/Padova, Italy, 242-258.

[2]. Al-Omari, Y., 1994. Mineralogical and Engineering Properties of Clayey Beds Failure Areas along the Irbid-Jerash-Amman and Amman-Na'ur-Dead Sea Highways. MSc thesis, Dept. of Geology \& Mineralogy, Jordan University, Amman.

[3]. Arab Center for Engineering Studies (ACES), 1993. Site and Geotechnical Investigation for the Sliding side Slopes Encountered along the Proposed Jerash-Irbid Road (under Construction) at Station $\mathrm{Km} 39+200$ to $\mathrm{Km} 93+600$. Report submitted to the Ministry of Public Works and Housing, Amman.

[4]. Bhat B., Venketesh N. Singh S. and Jha S (2012) Land Degradation by Quarrying Operation, THE INDIAN SCIENCE CONGRESS RASHTRIYA KISHORE VAIGYANIK SAMMELAN 4th - 6th JAN, http://www.isc2012.com/pdf/children_science_congress_proceed ings.pdf. accessed3November 2012

[5]. Chen, Y. Q., 1983. Analysis of Deformation Surveys - A Generalized Method. Department of Surveying Engineering, University of New Brunswick, Technical Report No. 94.

[6]. Chen, Y. Q., and Retscher, G., 1998. Geodetic Surveys on Major Construction Sites in Hong Kong. Proceedings of the International Symposium on Geodesy for Geotechnical and Structural Engineering, Eisenstadt, Austria, 539-545.

[7]. Chrzanowski, A., Chen, Y. Q., and Secord J. M., 1982. On the Analysis of Deformation Surveys. Proceedings of the $4^{\text {th }}$ Canadian Symposium on Mining Surveying and Deformation Measurements. The Canadian Institute of Surveying, Banff, 7-9 June.

[8]. Crespi, M., 1996. A Software Package for the Adjustment and Analysis of GPS Control Networks. Reports on Surveying and Geodesy, Nautilus.

[9]. FUJISAWA, K., HARADA, T. \& TAKEDA, H. 2004. Observation of and emergency measures for a landslide in an urban area. The Foundation Engineering \& Equipments, Vol32, No.9, 19-23.

[10]. HARADA, T., FUJISAWA, K. \& TAKEDA, H. 2004. Countermeasures for landslide in an urban area - Example of Atami city, Shizuoka Pref. -. 43rd Colloquium of Japan Landslide Society, 61-64.

[11]. Kuang, S. L., 1996. Geodetic Network Analysis and Optimal Design: Concepts and Applications. Ph.D thesis. SAMS Publications.

[12]. Malkawi,.H., Fahmi, J., Al-Sheriadeh, M., and Abederahman, N., 1998. Geological, Engineering and Hydrological Evaluation of Landslides in Jordan. Final Report submitted to the Higher Council for Science and Technology, Amman, Jordan.

[13]. Malkawi, A.I.H., Saleh, B., Al-Sheriadeh, M.S., and Hamza, M.sh., 2000. Mapping of Landslide Hazard Zones in Jordan using Remote Sensing and GIS. ASCE, Journal of Urban Planning and Development. [126](1): 1-17.

[14]. Moke, E., 1998. Reliable Single Epoch GPS Processing Algorithm for Static Deformation Monitoring. Proceedings of the International Symposium on Geodesy for Geotechnical and Structural Engineering, Eisenstadt, Austria, 159-166.

[15]. Retscher, G., 1999. RTK-GPS Positioning and Navigation in Marine Geodesy. The Geomatics Journal of Hong Kong, No. 2, 39-48. 